\title{
Report of two protocol planned interim analyses in a randomised multicentre phase III study comparing capecitabine with fluorouracil and oxaliplatin with cisplatin in patients with advanced oesophagogastric cancer receiving ECF
}

\author{
K Sumpter', C Harper-Wynne', D Cunningham*,', S Rao', N Tebbutt', AR Norman', C Ward', T Iveson², \\ M Nicolson ${ }^{3}$, T Hickish $^{4}, M_{\text {Hill }}^{1,5}$ and J Oates' \\ ${ }^{\prime}$ Royal Marsden NHS Trust, Down's Road, Sutton, Surrey, UK; ${ }^{2}$ Royal South Hants Hospital, Southampton, and Salisbury District Hospital, UK; ${ }^{3}$ Oncology \\ - Anchor Unit, Aberdeen Royal Infirmany, Aberdeen, UK; ${ }^{4}$ Dorset Cancer Network, Royal Bournemouth Hospital, Bournemouth, UK; ${ }^{5}$ Kent Oncology \\ Centre, Hermitage Lane, Maidstone, UK
}

The purpose of the study was to establish the optimal dose of capecitabine $(X)$ to be used within a multicentre, randomised study evaluating the potential roles of oxaliplatin $(O)$ and $X$ in chemonaive patients (pts) with advanced oesophagogastric cancer. Two by two design was used, and pts were randomised to one of four regimens and stratified for extent of disease, performance status (PS) and centre. The treatment regimens are epirubicin, cisplatin, 5-fluorouracil (ECF), EOF, ECX or EOX. Doses: E $50 \mathrm{mg} \mathrm{m}^{-2}$ C $60 \mathrm{mg} \mathrm{m}^{-2}$ and $\bigcirc 130 \mathrm{mg} \mathrm{m}^{-2}$ i.v. 3 weekly; F $200 \mathrm{mg} \mathrm{m}^{-2}$ day $^{-1}$ i.v. and $\times 500 \mathrm{mg} \mathrm{m}^{-2}$ b.i.d. $^{-1}$ (escalated to $625 \mathrm{mg} \mathrm{m}^{-2}$ b.i.d. $^{-1}$ after results of first interim analysis) p.o., continuously. First interim analysis was performed when 80 pts had been randomised. Doselimiting fluoropyrimidine toxicities were stomatitis, palmar plantar erythema (PPE) and diarrhoea; 5. $1 \%$ of X-treated pts experienced grade $3 / 4$ toxicity. Protocol planned dose escalation of $X$ to $625 \mathrm{mg} \mathrm{m}^{-2}$ b.i.d. ${ }^{-1}$ was instituted and a second interim analysis has been performed; results are presented in this paper. A total of 204 pts were randomised at the time of the protocol planned $2 \mathrm{nd}$ interim analysis. Grade 3/4 fluoropyrimidine-related toxicity was seen in $13.7 \%$ pts receiving F, $8.4 \%$ pts receiving $\times 500 \mathrm{mg} \mathrm{m}^{-2}$ b.i.d. $^{-1}$ and 14.7\% pts receiving $\times 625 \mathrm{mg} \mathrm{m}^{-2}$ b.i.d. $^{-1}$. Combined complete and partial response rates were ECF 31\% (95\% Cl I 8.7-46.3), EOF 39\% (95\% Cl 25.9-53.I), ECX 35\% (95\% Cl 21.4-50.3), EOX 48\% (95\% Cl 33.3-62.8). Grade 3/4 fluoropyrimidine toxicity affected $14.7 \%$ of pts treated with $\times 625 \mathrm{mg} \mathrm{m}^{-2}$ b.i.d. $^{-1}$, which is similar to that observed with $\mathrm{F}$, confirming this to be the optimal dose. The replacement of $\mathrm{C}$ by $\mathrm{O}$ and $\mathrm{F}$ by $X$ does not appear to impair efficacy. The trial continues to total accrual of 1000 pts. British Journal of Cancer (2005) 92, 1976-1983. doi:I0.1038/sj.bjc.6602572 www.bjcancer.com

(c) 2005 Cancer Research UK

Oesophagogastric (OG) cancer is the second most common cancer worldwide and while the incidence of gastric cancer is falling, that of adenocarcinoma of the OG junction is rising. The majority of pts present with inoperable or metastatic disease and consequently 5 -year survival rates are only $10-15 \%$ (CRC, 1995). In advanced disease, palliative chemotherapy has been shown to improve survival and quality of life (QOL) when compared to bestsupportive care alone (Murad et al, 1993; Pyrhonen et al, 1995; Glimelius et al, 1997).

* Correspondence: Professor D Cunningham, Department of Medicine, Royal Marsden Hospital, Down's Road, Sutton, Surrey SM2 5PT, UK;

E-mail: david.cunningham@icr.ac.uk

Support for this trial is provided by SANOFI-SYNTHELABO and ROCHE Pharmaceuticals. This study is now an NCRI adopted trial.

Presented as an oral presentation ASCO 2002 and a poster discussion ASCO 2003.

Received I January 2005; revised I4 March 2005; accepted I4 March 2005
One of the reference regimens for this disease is epirubicin, cisplatin and protracted venous infusion 5-fluorouracil (ECF) (Cunningham et al, 1991). This regimen was developed at the Royal Marsden Hospital, and in phase II studies response rates of 55-67\% were observed (Evans et al, 1992; Harper et al, 1992; Melcher and Maughan, 1994; Zaniboni et al, 1995; Bamias et al, 1996). ECF, when compared to FAMTX in a prospective randomised clinical trial (RCT), demonstrated superior response rates (45 vs 21\%), overall survival and QOL (Webb et al, 1997). A further RCT comparing ECF to MCF (substituting E with mitomycin C) confirmed similar efficacy for the two regimens: response rates ECF $42.2 \%$ and MCF $44.1 \%(P=0.692)$ and median survival 9.4 and 8.7 months, respectively $(P=0.315)$. Global QOL, however, was superior with ECF (Ross et al, 2002).

Oxaliplatin (O) is a third-generation diaminocyclohexane platinum compound, proven to be active in various tumour types. Oxaliplatin has demonstrated synergy with 5-fluorouracil (5FU) in advanced colorectal cancer (Raymond et al, 2001). In the firstline treatment of advanced colorectal cancer, the combination of $\mathrm{O}$ and 5FU has response rates of 36-58\% (Levi et al, 1992, 1994; 
De Gramont et al, 2000) and this is now an established treatment in this setting (Goldberg et al, 2004). In addition, activity of this combination has been demonstrated in advanced gastric cancer, with a response rate of $45 \%$ and a median overall survival of 8.6 months (Louvet et al, 2002). Also, in 26 pts previously treated with $5 \mathrm{FU}$, with a bimonthly $\mathrm{O}$ and 5FU/LV bolus and infusional regimen, the response rate was $26 \%$ and the median overall survival was 7.3 months (Kim et al, 2003). Cisplatin is associated with peripheral neuropathy, renal toxicity, high frequency nerve deafness and emesis; it also requires intravenous hydration. Oxaliplatin does not cause any clinically significant renal toxicity or ototoxicity and the dose-limiting toxicity is a peripheral sensory neuropathy, which is usually reversible but cumulative. The unique activity of $\mathrm{O}$ in colorectal cancer, the preliminary interesting results in gastric cancer and its improved toxicity profile compared to cisplatin suggest the potential for improved results in OG cancer.

Capecitabine $(\mathrm{X})$ is an oral fluoropyrimidine, which is absorbed from the gastrointestinal tract as an intact molecule, metabolised primarily in the liver and converted in tumour tissues to $5 \mathrm{FU}$ by the enzyme thymidine phosphorylase (found in higher concentrations in tumour cells than normal cells). In advanced colorectal cancer, two RCTs have shown X to be at least as effective as 5FU/ LV (Mayo regimen) in terms of overall survival, with a better toxicity profile (Hoff et al, 2001; Van Cutsem et al, 2001). Capecitabine is known to be active in advanced gastric cancer, with a single agent response rate in chemonaive pts of $24 \%$ (Koizumi et al, 2003). A phase II study involving X $1250 \mathrm{mg} \mathrm{m}^{-2}$ day $^{-1} \mathrm{D} 1-$ 14 and cisplatin $60 \mathrm{mg} \mathrm{m}^{-2}$ day $^{-1} \mathrm{D} 1$ every 3 weeks, for first-line treatment of advanced gastric cancer, resulted in an overall response rate of $54 \%$ and a median survival of 10.1 months (Kim et al, 2002).

To achieve the synergistic effects of fluoropyrimidines in combination with platinum compounds, thymidylate synthase inhibition is required prior to platinum administration (Cho et al, 2002). Preclinical studies have confirmed that a twice daily dosing of $\mathrm{X}$ will ensure efficient thymidylate synthase inhibition. A continuous twice daily X monotherapy schedule has been studied in a phase I trial (Budman et al, 1998). The maximum tolerated dose was $1657 \mathrm{mg} \mathrm{m}^{-2} \mathrm{day}^{-1}$ and the recommended dose for phase II studies was $1331 \mathrm{mg} \mathrm{m}^{-2} \mathrm{day}^{-1}$. The conclusions of a phase I study of the combination of $\mathrm{O}$ and $\mathrm{X}$ in advanced solid tumours recommended a dose of X $1000 \mathrm{mg} \mathrm{m}^{-2}$ b.i.d. ${ }^{-1} \mathrm{D} 1-14(80 \%$ of the monotherapy dose) in combination with $\mathrm{O} 130 \mathrm{mg} \mathrm{m}^{-2}$ every 3 weeks (Diaz-Rubio et al, 2002). The dose-limiting toxicity of the combination was diarrhoea and the combination resulted in limited additional haematological toxicity.

In this study, it was not expected that the proposed starting dose of $\mathrm{X}$ of $500 \mathrm{mg} \mathrm{m}^{-2}$ b.i.d. ${ }^{-1}$ continuously ( $75 \%$ of monotherapy dose) would lead to more toxicity than PVI 5FU $200 \mathrm{mg} \mathrm{m}^{-2}$. The purpose of this study was, therefore, to establish the optimal dose of $\mathrm{X}$ in the initial phase of this randomised trial by incorporating a dose escalation/de-escalation. We report the results of this initial phase and the subsequent planned second interim analysis.

\section{PATIENTS AND METHODS}

\section{Study design}

The study uses a two by two randomisation to compare X with PVI 5FU and $\mathrm{O}$ with cisplatin. The first 80 pts were randomised in a pilot phase II study, permitting dose escalation/de-escalation in the event of protocol-defined differences in fluoropyrimidine-dependent Common Toxicity Criteria (CTC) grade 3/4 toxicity in the $\mathrm{X}$ study arms. Fluoropyrimidine-related toxicity (stomatitis, palmar-plantar erythema (PPE) and diarrhoea) was analysed in a first planned interim analysis, according to fluoropyrimidine containing regimen. It was planned that if the grade $3 / 4$ fluoropyrimidine-related toxicity of this dose of $\mathrm{X}$ was $<10 \%$, the dose of X would be increased by $25 \%$, if the grade $3 / 4$ fluoropyrimidine toxicity was $11-29 \%$, the dose would remain unchanged and if it was $>30 \%$ the dose would be reduced by $25 \%$. Following determination of the dose of $\mathrm{X}$ to be used in the chemotherapy combinations (first interim analysis), the multicentre phase III trial was opened to recruitment and a second interim analysis was planned at 200 pts. This paper reports the results of the first and second preplanned interim analyses. Figure 1 summarises the trial design employed.

\section{Patient eligibility}

Patients were required to have histologically verified locally advanced or metastatic adenocarcinoma, squamous cell or undifferentiated carcinoma of the oespohagus, oesophagogastric junction (OGJ) or stomach. The primary tumour was classified as inoperable on the basis of either findings at laparotomy or computed tomography (CT) scan and endoscopic ultrasound results. Patients could not have received any previous chemotherapy or radiotherapy unless the latter was adjuvant treatment with relapse outside the radiotherapy field. Patients were required to have adequate bone marrow (platelets $>100 \times 10^{9} 1^{-1}$, WBC count $>3 \times 10^{9} 1^{-1}$ ), renal (glomerular filtration rate $\geqslant 60 \mathrm{ml} \mathrm{min}^{-1}$ and serum creatinine within normal range) and hepatic (bilirubin $<2 \times$ upper limit of normal range) function, Eastern Cooperative Oncology Group performance status $0-2$, life expectancy of at least 3 months and no concurrent uncontrolled medical illness. If there was a suspicion of left ventricular dysfunction, amultigated cardiac scan was performed and pts were excluded if this was below the reference range for the institution. The study was approved by the Scientific and Research Ethics Committees of the participating institutions and all participants gave written informed consent before entering the study.

\section{Pretreatment evaluation}

A full history was taken and an examination was performed on pts prior to treatment. Baseline full blood count, clotting screen, urea and electrolytes, liver function tests and carcinoembryonic antigen were performed in all pts. All pts had a baseline CXR and CT scan of chest, abdomen and pelvis within 28 days of commencing treatment. Upper GI endoscopy was performed at baseline unless pts had a histological diagnosis obtained at a laparotomy; baseline EDTA clearance or $24 \mathrm{~h}$ urinary creatinine clearance was measured prior to randomisation and baseline QOL was measured using the European Organisation for Research and Treatment of Cancer (EORTC) core 30 questionnaire.

\section{Study protocol}

Dual lumen Hickman lines were inserted via the Seldinger technique, under local anaesthetic, in patient's randomised to either of the PVI 5FU containing combinations. On the day of the insertion of the Hickman line, pts were started on warfarin $1 \mathrm{mg} \mathrm{day}^{-1}$ as prophylaxis for line-related thrombosis. The four arms of treatment were as follows:

ECF regimen: Epirubicin $50 \mathrm{mg} \mathrm{m}^{-2}$ i.v. bolus every 3 weeks, cisplatin $60 \mathrm{mg} \mathrm{m}^{-2}$ with standard hydration every 3 weeks (Findlay et al, 1994), 5FU $200 \mathrm{mg} \mathrm{m}^{-2}$ daily by continuous infusion via central line.

EOF regimen: Epirubicin $50 \mathrm{mg} \mathrm{m}^{-2}$ i.v. bolus every 3 weeks, $\mathrm{O} 130 \mathrm{mg} \mathrm{m}^{-2}$ i.v. infusion over $2 \mathrm{~h}$ every 3 weeks, $5 \mathrm{FU} 200 \mathrm{mg} \mathrm{m}^{-2}$ daily by continuous infusion via central line.

ECX regimen: Epirubicin $50 \mathrm{mg} \mathrm{m}^{-2}$ i.v. bolus every 3 weeks, cisplatin $60 \mathrm{mg} \mathrm{m}^{-2}$ with standard hydration every 3 weeks (Findlay et al, 1994), X 500-625 $\mathrm{mg} \mathrm{m}^{-2}$ b.i.d. $^{-1}$ orally continuously. 
dexamethasone $8 \mathrm{mg}$ i.v. be given prechemotherapy and dexamethasone $4 \mathrm{mg}$ p.o. tds for 2 days and metoclopramide $10 \mathrm{mg}$ tds for 3 days postchemotherapy. Planned treatment duration was 24 weeks. Response was evaluated at 12 and 24 weeks.

\section{Evaluation of toxicity}

Toxicity was graded according to the National Cancer Institute common toxicity criteria (CTC) version 2. Dose modifications for ECF were made according to previously published guidelines (Findlay et al, 1994). Dose modifications of the E, cisplatin and PVI 5 -FU in the EOF, ECX and EOX regimens were made according to the guidelines for ECF. Oxaliplatin was delayed for 1 week if neutrophil count $<1.0 \times 10^{9} 1^{-1}$, platelet count $<75 \times 10^{9} 1^{-1}$ or the patient had persistent grade 1 or 2 neuropathy. After recovery from grade 2-4 thrombocytopenia or grade 3/4 neutropenia, the dose of $\mathrm{O}$ was reduced to $100 \mathrm{mg} \mathrm{m}^{-2}$. On recovery of persistent grade $1 / 2$ neuropathy between cycles or grade $3 / 4$ neuropathy for 7-14 days, the dose of $\mathrm{O}$ was dose reduced to $100 \mathrm{mg} \mathrm{m}^{-2}$. In the event of persistent grade 3/4 neuropathy, further $\mathrm{O}$ was omitted and carboplatin could be substituted at the investigators discretion. If laryngeal dysaesthesia occurred, subsequent $O$ was administered as a 6-h infusion. If grade 3/4 diarrhoea or stomatitis occurred despite appropriate fluoropyrimidine dose reductions, subsequent $\mathrm{O}$ was reduced to $100 \mathrm{mg} \mathrm{m}^{-2}$. Capecitabine was stopped if pts developed grade $2-3$ stomatitis, diarrhoea or nausea and vomiting. If grade 3 toxicity was controlled adequately within 2 days and on resolution of grade 2 toxicity, $\mathrm{X}$ was continued at full dose. If grade 2 toxicity occurred a second time, $\mathrm{X}$ was dose reduced by $25 \%$, a third time by $50 \%$ and if it occurred a fourth time treatment was discontinued. If grade 3 toxicity took longer than 2 days to resolve, $\mathrm{X}$ was dose reduced by $25 \%$. If grade 3 toxicity occurred a second time $\mathrm{X}$ was dose reduced by $50 \%$ and discontinued if it occurred a third time. If grade 4 stomatitis, diarrhoea or nausea and vomiting occurred, $\mathrm{X}$ could either be discontinued or dose reduced by $50 \%$, at the investigator's discretion. For $\mathrm{X}$ associated PPE, pyridoxine $50 \mathrm{mg}$ tds was commenced and the following modifications were made: grade 1 - no modification, grade 2 - X stopped until resolution and then dose reduced by $15 \%$, grade 3 - X stopped until resolution and then dose reduced by $30 \%$, for recurrent grade 3 - X stopped until resolution and then dose reduced by $50 \%$.

\section{Assessment of response}

Response is assessed according to the revised WHO criteria with RECIST guidelines (Therasse et al, 2000). A complete response (CR) is the disappearance of all target lesions. A partial response (PR) is at least a $30 \%$ decrease in the sum of the longest diameter of target lesions, taking as reference the baseline sum longest diameter. Progressive disease is at least a $20 \%$ increase in the sum of the longest diameter of a target lesion, taking as reference the smallest sum longest diameter recorded since the treatment started or the appearance of one or more new lesions. Stable disease is neither sufficient shrinkage for a partial response, nor sufficient increase to qualify for progressive disease, taking as reference the smallest sum longest diameter since the treatment started. Endoscopic response is used to assess the primary tumour: CR is no evidence of endoluminal disease and negative histology on biopsy; PR in the primary site must have CT evidence of a PR and $50 \%$ reduction in the endoscopic appearances of the tumour; SD must be shown on CT scanning; PD at endoscopy classifies overall as PD regardless of response at other evaluable sites.

Patients completed the EORTC QLQ-C30 version 3.0 QOL assessment prior to randomisation and at 3, 6, 9 and 12 months (Aaronson et al, 1993). 


\section{Statistical methods}

The primary end point of this phase III trial is overall survival and secondary end points are failure-free survival, response, duration of response, time to progression, toxicity and QOL. Patient numbers are based on a 1-year survival of $35 \%$ for ECF. A planned total of 1000 pts will be randomised allowing noninferiority to be demonstrated. An improvement in 1-year survival with any of the joint arm combinations (e.g. ECF + EOF $v s$ ECX + EOX) from 35 to $44 \%$ could be detected with at least $80 \%$ power, or for an improvement from 35 to $45 \%$ with at least $90 \%$ power (twosided test, alpha 5\%). An improvement in 1-year survival with any of the combinations could be detected from 35 to $46 \%$ with $90 \%$ (two-sided test, alpha $=5 \%$ ). Randomisation is allocated by telephone, and is stratified for performance status, centre and locally advanced $v s$ metastatic disease. We are now reporting the two planned interim analyses within this study.

\section{RESULTS}

A total of 204 pts were randomised from 18 oncology centres in the UK between June 2000 and October 2002. The first 80 pts were recruited from four centres and in October 2001, the toxicity data on these pts was analysed and presented to the data monitoring committee (first planned interim analysis). Of the 204 pts, two were ineligible (one had a synchronous lung primary, one was unable to start treatment within 30 days of baseline CT evaluation), three were randomised but did not receive treatment (one patient withdrew consent and two deteriorated clinically and were withdrawn from the study prior to starting treatment) and one patient received treatment in violation with the protocol. A total of 198 pts were, therefore, evaluable for toxicity and response. In total, 53 pts were randomised to ECF, 48 to ECX, 55 to EOF and 48 to EOX. Treatment groups were well balanced for patient characteristics (Table 1).

In the first planned interim analysis, the first 80 pts were analysed for toxicity. Fluoropyrimidine-related toxicity (stomatitis, palmar-plantar erythema (PPE) and diarrhoea) was analysed according to fluoropyrimidine-containing regimen. The grade $3 / 4$ fluoropyrimidine-related toxicity, in pts receiving $\mathrm{X} 500 \mathrm{mg} \mathrm{m}^{-2}$ b.i.d., was $5.1 \%$; hence, the dose of $\mathrm{X}$ was escalated to $625 \mathrm{mg} \mathrm{m}^{-2}$ b.i.d. (Tebbutt et al, 2002). The trial protocol was amended to include this dose escalation and ethical approval was obtained by all the participating centres. The second interim analysis was performed when 204 pts had been recruited. Figure 2 illustrates the number of pts receiving each of the fluoropyrimidine doses: 103 pts received F $200 \mathrm{mg} \mathrm{m}^{-2}$ day $^{-1}, 60$ pts X $500 \mathrm{mg} \mathrm{m}^{-2}$ b.i.d. ${ }^{-1}$ and 35 pts X $625 \mathrm{mg} \mathrm{m}^{-2}$ b.i.d. ${ }^{-1}$

\section{Toxicity}

Median number of chemotherapy cycles administered was 6 in each of the treatment arms. Grade 3/4 fluoropyrimidine-related

Table I Patient characteristics

\begin{tabular}{|c|c|c|c|c|}
\hline \multirow[b]{2}{*}{ Treatment arm } & \multicolumn{4}{|c|}{ No. of patients } \\
\hline & ECF & EOF & ECX & EOX \\
\hline $\begin{array}{l}\text { Randomisation ( } n \text { ) } \\
\text { Age (years) }\end{array}$ & 53 & 55 & 48 & 48 \\
\hline \multicolumn{4}{|l|}{ Age (years) } & 64 \\
\hline Range & $40-77$ & $45-76$ & $34-81$ & $37-79$ \\
\hline \multicolumn{5}{|l|}{ Sex } \\
\hline Female & 9 & 8 & 14 & 12 \\
\hline Male & 39 & 40 & 41 & 41 \\
\hline \multicolumn{5}{|l|}{ Performance status } \\
\hline $0 / 1$ & 46 & 48 & 42 & 42 \\
\hline 2 & 7 & 7 & 6 & 6 \\
\hline \multicolumn{5}{|l|}{ Primary site } \\
\hline Oesophagus & 21 & 20 & 13 & 14 \\
\hline OG & 19 & 15 & 16 & 15 \\
\hline Gastric & 12 & 20 & 18 & 19 \\
\hline Unknown & । & 0 & I & 0 \\
\hline \multicolumn{5}{|l|}{ Histology } \\
\hline Adenocarcinoma & 44 & 48 & 41 & 41 \\
\hline Squamous carcinoma & 5 & 6 & 6 & 5 \\
\hline Other & 3 & I & 0 & 1 \\
\hline Unknown & I & 0 & I & 0 \\
\hline \multicolumn{5}{|l|}{ Disease status } \\
\hline Locally advanced & 15 & 11 & 12 & 17 \\
\hline Metastatic & 38 & 44 & 36 & 31 \\
\hline Ineligible & I & 0 & I & 0 \\
\hline Randomised but not treated & 3 & 0 & 0 & 0 \\
\hline
\end{tabular}

$\mathrm{ECF}=$ epirubicin, cisplatin, 5-fluorouracil; $\mathrm{ECX}=$ epirubicin, cisplatin, capecitabine; $E O F=$ epirubicin, oxaliplatin, 5-fluorouracil; EOX = epirubicin, oxaliplatin, capecitabine; $O G J=$ oesophagogastric junction.

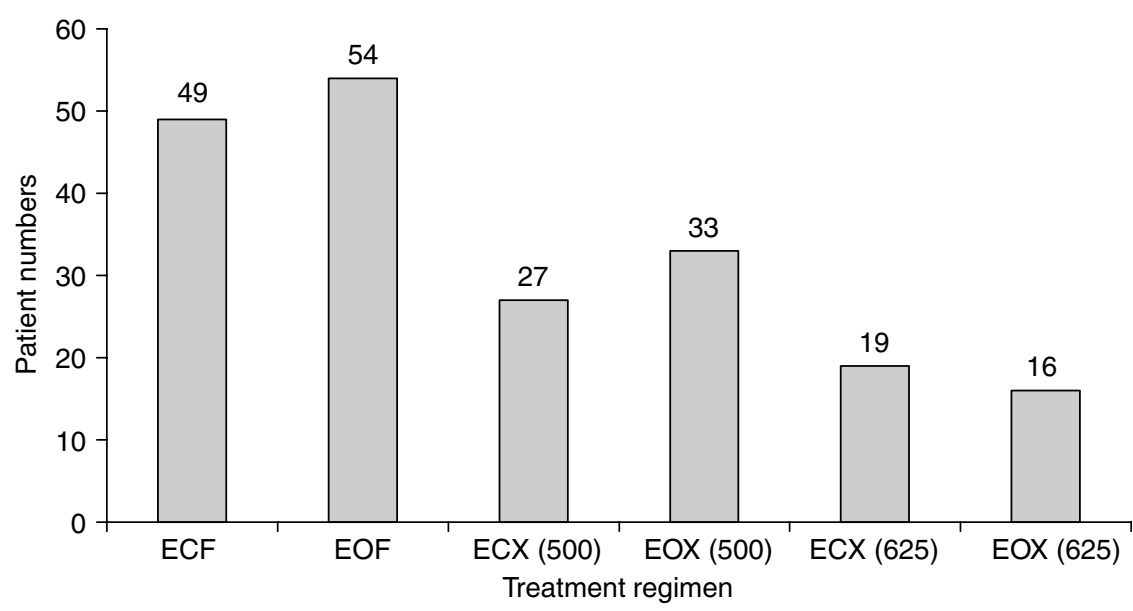

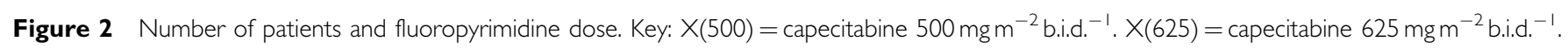


toxicity (estimated by patient not cycle) according to regimen and dose of fluoropyrimidine is shown in Table 2. The overall percentage of grade 3/4 fluoropyrimidine-related toxicity in pts receiving 5FU $200 \mathrm{mg} \mathrm{m}^{-2} \mathrm{day}^{-1}$ was $13.7 \%$ (95\% CI 7.4-22\%), for pts receiving X $500 \mathrm{mg} \mathrm{m}^{-2}$ b.i.d. $8.4 \%$ (95\% CI 2.8-18.7) and for pts receiving X $625 \mathrm{mg} \mathrm{m}^{-2}$ b.i.d. $14.7 \%$ (95\% CI $4.9-31$ ). All other toxicity was predictable and is shown in Table 3, according to treatment arm and in Table 4 according to treatment arm and dose of fluoropyrimidine.

\section{Dose intensity}

There were no significant differences in the dose intensity of fluoropyrimidine, E or platinum agent between the four treatment arms. The dose intensity of the drugs in ECF was E 90.7\%, cisplatin $91.9 \%$, $5 \mathrm{FU} 88.6 \%$; for ECX it was E $90.3 \%$, cisplatin $87.5 \%$, $\mathrm{X} 87.1 \%$; for $\mathrm{EOF}$ it was $\mathrm{E} 90 \%$, O 89.4\%, 5FU 82.1\%; for $\mathrm{EOX}$ it was $\mathrm{E} 87.5 \%$, O 87.1\%, $\mathrm{X} 83.3 \%$. Dose intensity according to fluorpyrimidine dosage is shown in Table 5.

\section{Response}

Of the 204 patient's randomised, 198 pts received chemotherapy within the clinical trial. Two pts had nonevaluable disease and therefore 196 pts were included in the response analysis on 12th May 2003. Objective response rates were seen in 15 pts (one CR, 14 PRs) treated with ECF for a response rate of $31 \%, 21$ pts (three CRs, 18 PRs) treated with EOF for a response rate of $39 \%, 16$ pts (four CRs, 12 PRs) treated with ECX for a response rate of $35 \%$ and 23 pts (one CR, 22 PRs) treated with EOX for a response rate of $48 \%$ (Table 6). The corresponding rates of progressive disease (PD) were $27 \%$ with ECF, $20 \%$ with EOF, $24 \%$ with ECX and $15 \%$ with EOX. There were 18 pts (three ECF, seven EOF, five ECX and three EOX) in whom no assessment was available. Of the eight pts

Table 2 Fluoropyrimidine toxicity according to treatment arm and dose of fluoropyrimidine

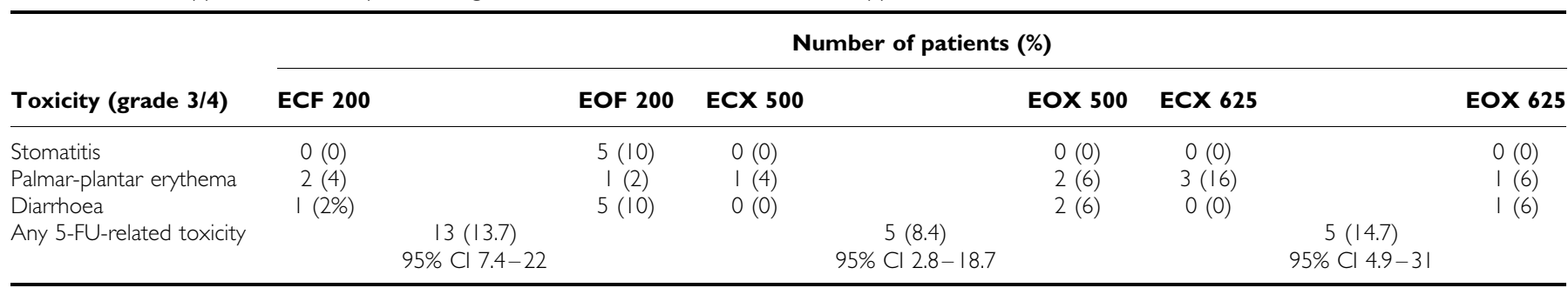

$\mathrm{ECF}=$ epirubicin, cisplatin, 5-fluorouracil; ECX = epirubicin, cisplatin, capecitabine; EOF = epirubicin, oxaliplatin, 5-fluorouracil; EOX = epirubicin, oxaliplatin, capecitabine.

Table 3 Non-fluoropyrimidine toxicity

\begin{tabular}{|c|c|c|c|c|c|c|c|c|}
\hline \multirow[b]{2}{*}{ Toxicity (grade 3/4) } & \multicolumn{2}{|l|}{ ECF } & \multicolumn{2}{|l|}{ EOF } & \multicolumn{2}{|l|}{ ECX } & \multicolumn{2}{|l|}{ EOX } \\
\hline & No. of pts/total & $\%$ & No. of pts/total & $\%$ & No. of pts/total & $\%$ & No. of pts/total & $\%$ \\
\hline Alopeciab $^{b}$ & $21 / 47$ & 50 & $18 / 50$ & 36 & $17 / 43$ & 40 & $13 / 48$ & 27 \\
\hline Lethargy & $8 / 46$ & 17 & $10 / 50$ & 20 & $4 / 43$ & 9 & $8 / 48$ & 17 \\
\hline Peripheral neuropathy ${ }^{\mathrm{a}}$ & $0 / 47$ & 0 & $3 / 50$ & 6 & $1 / 43$ & 2 & $2 / 48$ & 4 \\
\hline Neutropenia & $16 / 47$ & 34 & $12 / 49$ & 24 & $|6 / 4|$ & 39 & $19 / 48$ & 40 \\
\hline Febrile neutropenia & $2 / 24$ & 8 & $4 / 29$ & 14 & $1 / 24$ & 5 & $3 / 30$ & 10 \\
\hline Anaemia & $8 / 47$ & 17 & $2 / 49$ & 4 & $3 / 41$ & 7 & $4 / 48$ & 8 \\
\hline
\end{tabular}

${ }^{a}$ No grade 4 toxicity. ${ }^{b} \mathrm{CTC}$ grade 2 alopecia. Pts = patients; ECF = epirubicin, cisplatin, 5-fluorouracil; ECX = epirubicin, cisplatin, capecitabine; EOF = epirubicin, oxaliplatin, 5 fluorouracil; EOX = epirubicin, oxaliplatin, capecitabine.

Table 4 Non-fluoropyrimidine toxicity according to fluoropyrimidine dose

\begin{tabular}{|c|c|c|c|c|c|c|c|c|c|c|c|c|}
\hline \multirow[b]{2}{*}{ Toxicity (grade 3/4) } & \multicolumn{2}{|l|}{ ECF 200} & \multicolumn{2}{|l|}{ EOF 200} & \multicolumn{2}{|l|}{ ECX 500} & \multicolumn{2}{|l|}{ EOX 500} & \multicolumn{2}{|l|}{ ECX 625} & \multicolumn{2}{|l|}{ EOX 625} \\
\hline & No. of pts/total & $\%$ & No. of pts/total & $\%$ & No. of pts/total & $\%$ & No. of pts/total & $\%$ & No. of pts/total & $\%$ & No. of pts/total & $\%$ \\
\hline Alopecia $^{b}$ & $21 / 47$ & 50 & $18 / 50$ & 36 & $12 / 27$ & 44 & $10 / 32$ & 31 & $5 / 16$ & 31 & $3 / 16$ & 19 \\
\hline Lethargy & $8 / 46$ & 17 & $10 / 50$ & 20 & $3 / 27$ & 11 & $5 / 32$ & 16 & $1 / 16$ & 6 & $3 / 16$ & 19 \\
\hline Peripheral neuropathy ${ }^{\mathrm{a}}$ & $0 / 47$ & 0 & $3 / 50$ & 6 & 1/27 & 4 & $0 / 32$ & 0 & $0 / 16$ & 0 & $2 / 16$ & 12 \\
\hline Neutropenia & $16 / 47$ & 34 & $12 / 49$ & 24 & $9 / 25$ & 36 & $15 / 32$ & 46 & $6 / 15$ & 40 & $4 / 16$ & 25 \\
\hline Febrile neutropenia & $2 / 24$ & 8 & $4 / 29$ & 14 & $1 / 10$ & 10 & $0 / 14$ & 0 & $0 / 14$ & 0 & $3 / 16$ & 19 \\
\hline Anaemia & $8 / 47$ & 17 & 2/49 & 4 & $2 / 26$ & 8 & $3 / 32$ & 9 & $1 / 15$ & 7 & $1 / 16$ & 6 \\
\hline
\end{tabular}

${ }^{a}$ No grade 4 toxicity. ${ }^{b} \mathrm{CTC}$ grade 2 alopecia. Pts = patients; ECF = epirubicin, cisplatin, 5-fluorouracil; ECX = epirubicin, cisplatin, capecitabine; EOF = epirubicin, oxaliplatin, 5 fluorouracil; EOX = epirubicin, oxaliplatin, capecitabine. 
Table 5 Dose intensity of chemotherapy agents received according to fluoropyrimidine and dose

\begin{tabular}{|c|c|c|c|c|}
\hline & \multirow[b]{2}{*}{ No. of pts } & \multicolumn{3}{|c|}{$\%$ of chemotherapy received } \\
\hline & & 5FU/capecitabine (\%) & Epirubicin (\%) & Platinum agent (\%) \\
\hline $\begin{array}{l}\text { 5FU } 200 \mathrm{mg} \mathrm{m}^{-2} \\
\text { Capecitabine } 500 \mathrm{mg} \mathrm{m}^{-2} \text { b.i.d. }^{-1} \\
\text { Capecitabine } 625 \mathrm{mg} \mathrm{m}^{-2} \text { b.i.d. }^{-1}\end{array}$ & $\begin{array}{r}104 \\
59 \\
35\end{array}$ & $\begin{array}{l}85.2 \\
87.2 \\
81.8\end{array}$ & $\begin{array}{l}90.3 \\
88.9 \\
88.8\end{array}$ & $\begin{array}{l}90.6 \\
87.8 \\
86.4\end{array}$ \\
\hline
\end{tabular}

Pts = patients; ECF = epirubicin, cisplatin, 5-fluorouracil (5FU); ECX = epirubicin, cisplatin, capecitabine; EOF = epirubicin, oxaliplatin, 5-fluorouracil; EOX = epirubicin, oxaliplatin, capecitabine.

Table 6 Response rates according to treatment arm

\begin{tabular}{|c|c|c|c|c|c|c|c|c|}
\hline & \multicolumn{2}{|c|}{ ECF } & \multicolumn{2}{|c|}{ EOF } & \multicolumn{2}{|c|}{ ECX } & \multicolumn{2}{|c|}{ EOX } \\
\hline & No. of pts & $\%$ & No. of pts & $\%$ & No. of pts & $\%$ & No. of pts & $\%$ \\
\hline PR & 14 & 29 & 18 & 33 & 12 & 26 & 22 & 46 \\
\hline Overall (CR+PR) & 15 & 31 & 21 & 39 & 16 & 35 & 23 & 48 \\
\hline $95 \% \mathrm{Cl}$ & & $(18.7-46.3)$ & & $(25.9-53.1)$ & & $(21.4-50.3)$ & & $(33.3-62.8)$ \\
\hline Stable disease & 17 & 36 & 16 & 30 & 14 & 30 & 15 & 31 \\
\hline
\end{tabular}

Pts = patients; ECF = epirubicin, cisplatin, 5-fluorouracil; ECX = epirubicin, cisplatin, capecitabine; EOF = epirubicin, oxaliplatin, 5-fluorouracil; EOX = epirubicin, oxaliplatin, capecitabine; $C R=$ complete response; $P R=$ partial response; $P D=$ progressive disease; $95 \% \mathrm{Cl}=95 \%$ confidence interval.

who achieved a CR, four were achieved after downstaging chemotherapy and surgery.

The objective response rates of patients receiving fluoropyrimidine or platinum agent are shown Tables 7 and 8 , respectively. Objective responses were seen in 36 pts (four CRs, 32 PRs) treated in either of the two 5FU-containing arms (ECF + EOF) for a response rate of $36 \%$, and in 39 pts (five CRs, 34 PRs) treated in either of the two X-containing arms (ECX $+\mathrm{EOX})$ for a response rate of $41 \%$. Objective responses were seen in 31 pts (five CRs, 26 PRs) treated in either of the cisplatin-containing arms (ECF + ECX) for a response rate of $33 \%$, and in 44 pts (four CRs. 40 PRs) treated in either of the $\mathrm{O}$-containing arms (EOF + EOX) for a response rate of $43 \%$

\section{DISCUSSION}

The purpose of the planned interim analyses presented in this paper was to establish the optimal dose of continuously administered $\mathrm{X}$ to be used in combination with either $\mathrm{E}$ and cisplatin or $\mathrm{E}$ and $\mathrm{O}$ in pts with advanced $\mathrm{OG}$ cancer, and to confirm the safety of any dose adjustment. The results of the first interim analysis demonstrated grade $3 / 4$ fluoropyrimidine toxicity in $5.1 \%$ of pts receiving X $500 \mathrm{mg} \mathrm{m}^{-2}$ b.i.d. ${ }^{-1}$ (Tebbutt et al, 2002). This resulted in the protocol planned dose escalation of $\mathrm{X}$ from 500 to $625 \mathrm{mg} \mathrm{m}^{-2}$ b.i.d. ${ }^{-1}$. The second analysis, performed when 204 pts had been randomized, confirmed that the dose of $625 \mathrm{mg} \mathrm{m}^{-2}$ b.i.d. ${ }^{-1}$ was safe. In all, $14.7 \%$ of pts treated with $\mathrm{X} 625 \mathrm{mg} \mathrm{m}^{-2}$ b.i.d. ${ }^{-1}$ experienced grade $3 / 4$ fluoropyrimidinerelated toxicity, which parallels that of PVI 5FU (13.7\%), confirming that this is the optimal dose of $\mathrm{X}$ to be used in combination with either $\mathrm{E}$ and cisplatin or $\mathrm{E}$ and $\mathrm{O}$.

A previous phase I study has evaluated the combination of $\mathrm{X}$ with $\mathrm{E} 50 \mathrm{mg} \mathrm{m}^{-2}$ and $\mathrm{C} 60 \mathrm{mg} \mathrm{m}^{-2}$, in pts with advanced OG cancer (Evans et al, 2002). They evaluated the dose-limiting toxicity (DLT) and maximum tolerated dose of $\mathrm{X}$ with escalations of $\mathrm{X}$ up to $1250 \mathrm{mg} \mathrm{m}^{-2}$ b.i.d. ${ }^{-1} \mathrm{D} 1-14$ with 7 days rest. The recommended dose of $\mathrm{X}$ for use on an intermittent schedule in combination with $\mathrm{E}$ and cisplatin was $1000 \mathrm{mg} \mathrm{m}^{-2}$ b.i.d. ${ }^{-1}$. There
Table 7 Response rates of patients receiving fluoropyrimidine treatment

\begin{tabular}{lcccccc}
\hline & \multicolumn{2}{c}{5 -FU arms } & & \multicolumn{2}{c}{ Capecitabine arms } \\
\cline { 2 - 3 } \cline { 5 - 6 } & No. of pts & $\%$ & & No. of pts & $\%$ \\
\hline CR & 4 & 4 & & 5 & 5 \\
PR & 32 & 32 & & 34 & 36 \\
Overall & 36 & 36 & & 39 & 41 \\
$95 \%$ Cl & 33 & $(26.6-46.2)$ & & $31.4-52.1)$ \\
SD & 24 & 24 & & 18 & 30 \\
PD & 9 & 8 & & 8 & 19 \\
No assessment available & 9 & & &
\end{tabular}

Pts = patients; $C R=$ complete response; $P R=$ partial response; $P D=$ progressive disease; $\mathrm{SD}=$ stable disease; $95 \% \mathrm{Cl}=95 \%$ confidence interval.

Table 8 Response rates of patients receiving platinum treatment

\begin{tabular}{lcccccc}
\hline & \multicolumn{2}{c}{ Cisplatin arms } & & \multicolumn{2}{c}{ Oxaliplatin arms } \\
\cline { 2 - 3 } \cline { 6 - 7 } & No. of pts & $\%$ & & No. of pts & $\%$ \\
\hline CR & 5 & 5 & & 4 & 4 \\
PR & 26 & 28 & & 40 & 39 \\
Overall & 31 & 33 & & 44 & 43 \\
$95 \%$ Cl & 31 & $(23.6-43.3)$ & & $34.1-54.3)$ \\
SD & 24 & 33 & & 31 & 30 \\
PD & 8 & 26 & & 18 & 18 \\
No assessment available & 8 & & 9 & 9 \\
\hline
\end{tabular}

Pts = patients; $C R=$ complete response; $P R=$ partial response; $P D=$ progressive disease; $\mathrm{SD}=$ stable disease; $95 \% \mathrm{Cl}=95 \%$ confidence interval.

have been no phase I studies looking at this combination using a continuous schedule of X; however, the results of our study have identified X $625 \mathrm{mg} \mathrm{m}^{-2}$ b.i.d. ${ }^{-1}$ to be the optimal dose in both an ECX and EOX regimen based on the similar incidence of fluoropyrimidine-related toxicity $(13.7 \%$ in $5 \mathrm{FU}$-containing arms and $14.7 \%$ in X $625 \mathrm{mg} \mathrm{m}^{-2}$ b.i.d. ${ }^{-1}$-containing arms). The nonfluoropyrimidine-related toxicity in all arms of this study was 
predictable and consistent with previous clinical trials (Ross et al, 2002). The rates of grade $3 / 4$ febrile neutropenia were $8 \%$ ECF, $14 \%$ EOF, 5\% ECX and 10\% EOX. However, the rate of grade $3 / 4$ febrile neutropenia in pts receiving EOX where $\mathrm{X}=625 \mathrm{mg} \mathrm{m}^{-2}$ b.i.d. ${ }^{-1}$ was $19 \%$ (three out of $16 \mathrm{pts}$ ), which is higher than any of the other arms. This may be due to relatively small patient numbers; however, the final analysis of this study will establish whether this is significant.

The primary end point of this study is to compare the overall survival in the four treatment arms and thus no survival data will be analysed until accrual is complete. The response rates indicate that $\mathrm{X}$ has efficacy similar to 5 -FU and that $\mathrm{O}$ appears to have promising activity in advanced OG cancer. It was not in the remit of this analysis to compare response rates and to draw firm conclusions from them at this stage would be erroneous. Patient preference is for oral chemotherapy regimen (Borner et $a l, 2002)$ and with the associated complications of the indwelling central venous catheter necessary with PVI-5FU, the replacement of $5 \mathrm{FU}$ with $\mathrm{X}$ would clearly be one of considerable benefit to pts.
In summary, we have presented the results of two planned interim analyses within a multicentre randomised study evaluating the role of $\mathrm{X}$ and $\mathrm{O}$ in advanced $\mathrm{OG}$ cancer. The results clearly confirm the safety of the dose escalation of $\mathrm{X}$ and demonstrate X $625 \mathrm{mg} \mathrm{m}^{-2}$ b.i.d. ${ }^{-1}$ continuously to be the dose that should be used in combination with the EC and EO regimens. In addition, our results show that $\mathrm{X}$ has similar efficacy to PVI 5-FU. The trial will continue to accrue to a planned target of 1000 pts.

\section{ACKNOWLEDGEMENTS}

We acknowledge the collaborating centres: St George's Hospital, London, UK; Broomfield Hospital, Chelmsford, UK; Ysbyty Gwynedd Hospital, Bangor, UK; Plymouth Hospital NHS Trust, UK; James Cook University Hospital, Middlesborough, UK; Mount Vernon Hospital, Middlesex, UK; Newcastle-upon-Tyne NHS Trust, UK; North Middlesex University Hospital NHS Trust, London, UK; Glan Clwyn Rhyl Hospital, Rhyl, UK; St Lukes Cancer Center, Guildford, UK; Velindre NHS Trust, Cardiff, UK; Western Park Hospital, Sheffield, UK.

\section{REFERENCES}

Aaronson NK, Ahmedzai S, Bergman B, Bullinger M, Cull A, Duez NJ, Filiberti A, Flechtner H, Fleishman SB, de Haes JC, Kaasa S, Klee M, Osoba D, Razavi D, Rofe PB, Schraub S, Sheeuev K, Sullivan M, Takeda E (1993) The European Organization for Research and Treatment of Cancer QLQ-C30: a quality-of-life instrument for use in international clinical trials in oncology. J Natl Cancer Inst 85: 365-376

Bamias A, Hill ME, Cunningham D, Norman AR, Ahmed FY, Webb A, Watson M, Hill AS, Nicolson MC, O’Brien ME, Evans TC, Nicolson V (1996) Epirubicin, cisplatin, and protracted venous infusion of 5fluorouracil for esophagogastric adenocarcinoma: response, toxicity, quality of life, and survival. Cancer 77: 1978-1985

Borner MM, Schoffski P, de Wit R, Caponigro F, Comella G, Sulkes A, Greim G, Peters GJ, van der Born K, Wanders J, de Boer RF, Martin C, Fumoleau P (2002) Patient preference and pharmacokinetics of oral modulated UFT $v s$ intravenous fluorouracil and leucovorin: a randomised crossover trial in advanced colorectal cancer. Eur J Cancer 38: $349-358$

Budman DR, Meropol NJ, Reigner B, Creaven PJ, Lichtman SM, Berghorn E, Behr J, Gordon RJ, Osterwalder B, Griffin T (1998) Preliminary studies of a novel oral fluoropyrimidine carbamate: capecitabine. J Clin Oncol 16: $1795-1802$

Cho H, Imada T, Oshima T, Shiozawa M, Rino Y, Takanashi Y (2002) Invitro effect of a combination of 5-fluorouracil (5-FU) and cisplatin (CDDP) on human gastric cancer cell lines: timing of cisplatin treatment. Gastric Cancer 5: $43-46$

Cancer Research Campaign Stomach Cancer, London, UK (1995) Cancer Research Campaign Factsheet 24.1.1995

Cunningham D, Mansi J, Ford HT (1991) Epirubicin, cisplatin and 5-fluorouracil (ECF) is highly effective in advanced gastric cancer. Proc Am Soc Clin Oncol 10: 136 (abstract 412)

De Gramont A, Figer A, Seymour M, Homerin M, Hmissi A, Cassidy J, Boni C, Cortes-Funes H, Cervantes A, Freyer G, Papamichael D, Le Bail N, Louvet C, Hendler D, de Braud F, Wilson C, Morvan F, Bonetti A (2000) Leucovorin and fluorouracil with or without oxaliplatin as first-line treatment in advanced colorectal cancer. J Clin Oncol 18: $2938-2947$

Diaz-Rubio E, Evans TR, Tabemero J, Cassidy J, Sastre J, Eatock M, Bisset D, Regueiro P, Baselga J (2002) Capecitabine (Xeloda) in combination with oxaliplatin: a phase I, dose-escalation study in patients with advanced or metastatic solid tumors. Ann Oncol 13: 558-565

Evans TR, Glees JP, Knight MJ (1992) The use of a new combination chemotherapy: epirubicin, cisplatin and continuous infusion 5-fluorouracil (ECF) in upper gastrointestinal (GI) tumours. Ann Oncol 3: 14 (Suppl 5)

Evans TR, Pentheroudakis G, Paul J, McInnes A, Blackie R, Raby N, Morrison R, Fullarton GM, Soukop M, McDonald AC (2002) A phase I and pharmacokinetic study of capecitabine in combination with epirubicin and cisplatin in patients with inoperable oesophago-gastric adenocarcinoma. Ann Oncol 13: $1469-1478$

Findlay M, Cunningham D, Norman A, Mansi J, Nicolson M, Hickish T, Nicolson V, Nash A, Sacks N, Ford H, Carter R, Hill A (1994) A phase II study in advanced gastro-esophageal cancer using epirubicin and cisplatin in combination with continuous infusion 5-fluorouracil (ECF). Ann Oncol 5: 609-616

Glimelius B, Ekstrom K, Hoffman K, Graf W, Sjoden PO, Haglund U, Svensson C, Enander LK, Linne T, Sellstrom H, Heuman R (1997) Randomized comparison between chemotherapy plus best supportive care with best supportive care in advanced gastric cancer. Ann Oncol 8: $163-168$

Goldberg RM, Sargent DJ, Morton RF, Fuchs CS, Ramanathan RK, Williamson SK, Findlay BP, Pitot HC, Alberts SR (2004) A randomized controlled trial of fluorouracil plus leucovorin, irinotecan, and oxaliplatin combinations in patients with previously untreated metastatic colorectal cancer. J Clin Oncol 22: 23-30, . Epub 2003 Dec 9.

Harper PG, Highley M, Houston S (1992) Significant palliation of advanced gastric/esophageal adenocarcinoma (g-o/c) with laser endoscopy and combination chemotherapy. Proc Am Soc Clin Oncol 11: 164 (abstract 472)

Hoff PM, Ansari R, Batist G, Cox J, Kocha W, Kuperminc M, Maroun J, Walde D, Weaver C, Harrison E, Burger HU, Osterwalder B, Wong AO, Wong R (2001) Comparison of oral capecitabine vs intravenous fluorouracil plus leucovorin as first-line treatment in 605 patients with metastatic colorectal cancer: results of a randomized phase III study. J Clin Oncol 19: 2282-2292

Kim DY, Kim JH, Lee SH, Kim TY, Heo DS, Bang YJ, Kim NK (2003) Phase II study of oxaliplatin, 5-fluorouracil and leucovorin in previously platinum-treated patients with advanced gastric cancer. Ann Oncol 14: $383-387$

Kim TW, Kang YK, Ahn JH, Chang HM, Yook JH, Oh ST, Kim BS, Lee JS (2002) Phase II study of capecitabine plus cisplatin as first-line chemotherapy in advanced gastric cancer. Ann Oncol 13: 1893-1898

Koizumi W, Saigenji K, Ujiie S, Terashima M, Sakata Y, Taguchi T (2003) A pilot phase II study of capecitabine in advanced or recurrent gastric cancer. Oncology 64: 232-236

Levi F, Misset JL, Brienza S, Adam R, Metzger G, Itzakhi M, Caussanel JP, Kunstlinger F, Lecouturier S, Descorps-Declere A, Jasmin C, Bismuth H, Reinburg A (1992) A chronopharmacologic phase II clinical trial with 5fluorouracil, folinic acid, and oxaliplatin using an ambulatory multichannel programmable pump. High antitumor effectiveness against metastatic colorectal cancer. Cancer 69: 893-900

Levi FA, Zidani R, Vannetzel JM, Perpoint B, Focan C, Faggiuolo R, Chollet P, Garufi C, Itzhaki M, Dogliotti L, Iacobelli S, Adam R, Kunstinger F, Gastiaburu J, Bismuth H, Jasmin C, Misset JL (1994) Chronomodulated $v s$ fixed-infusion-rate delivery of ambulatory chemotherapy with oxaliplatin, fluorouracil, and folinic acid (leucovorin) in patients with 
colorectal cancer metastases: a randomized multi-institutional trial. J Natl Cancer Inst 86: 1608-1617

Louvet C, Andre T, Tigaud JM, Gamelin E, Douillard JY, Brunet R, Francois E, Jacob JH, Levoir D, Taamma A, Rougier P, Cvitkovic E, de Gramont A (2002) Phase II study of oxaliplatin, fluorouracil, and folinic acid in locally advanced or metastatic gastric cancer patients. J Clin Oncol 20: $4543-4548$

Melcher AA, Maughan TS (1994) Neoadjuvant chemotherapy in gastroesophageal cancer using epirubicin, cisplatin and continuous infusion 5-fluorouracil (ECF). Br J Cancer 71: 15 (Suppl 24)

Murad AM, Santiago FF, Petroianu A, Rocha PR, Rodrigues MA, Rausch M (1993) Modified therapy with 5-fluorouracil, doxorubicin, and methotrexate in advanced gastric cancer. Cancer 72: 37-41

Pyrhonen S, Kuitunen T, Nyandoto P, Kouri M (1995) Randomised comparison of fluorouracil, epidoxorubicin and methotrexate (FEMTX) plus supportive care with supportive care alone in patients with nonresectable gastric cancer. $\mathrm{Br}$ J Cancer 71: 587-591

Raymond E, Faivre S, Coudray AM, Louvet C, Gespach C (2001) Preclinical studies of oxaliplatin in combination chemotherapy. Bull Cancer 88(Spec. no.): S26-S34

Ross P, Nicolson M, Cunningham D, Valle J, Seymour M, Harper P, Price T, Anderson H, Iveson T, Hickish T, Lofts F, Norman A (2002) Prospective randomized trial comparing mitomycin, cisplatin, and protracted venous-infusion fluorouracil (PVI 5-FU) With epirubicin, cisplatin, and PVI 5-FU in advanced esophagogastric cancer. J Clin Oncol 20: $1996-2004$

Tebbutt N, Norman A, Cunningham D, Iveson T, Nicolson M, Hickish T, Durrant C, Oates J, Hill M (2002) Randomised, multicentre phase III study comparing capecitabine with fluorouracil and oxaliplatin with cisplatin in patients with advanced oesophago-gastric cancer; interim analysis. Proc Am Soc Clin Oncol 2002 (abstract 523)

Therasse P, Arbuck SG, Eisenhauer EA, Wanders J, Kaplan RS, Rubinstein L, Verweij J, Van Glabbeke M, van Oosterom AT, Christian MC, Gwyther SG (2000) New guidelines to evaluate the response to treatment in solid tumors. European Organization for Research and Treatment of Cancer, National Cancer Institute of the United States, National Cancer Institute of Canada. J Natl Cancer Inst 92: 205-216

Van Cutsem E, Twelves C, Cassidy J, Allman D, Bajetta E, Boyer M, Bugat R, Findlay M, Frings S, Jahn M, McKendrick J, Osterwalder B, Perez-Manga G, Rosso R, Rougier P, Schmiegel WH, Seitz JF, Thompson P, Vieitez JM, Weitzel C, Harper P (2001) Oral capecitabine compared with intravenous fluorouracil plus leucovorin in patients with metastatic colorectal cancer: results of a large phase III study. J Clin Oncol 19: 4097-4106

Webb A, Cunningham D, Scarffe JH, Harper P, Norman A, Joffe JK, Hughes M, Mansi J, Findlay M, Hill A, Oates J, Nicolson M, Hickish T, O’Brien M, Iveson T, Watson M, Underhill C, Wardley A, Meehan M (1997) Randomized trial comparing epirubicin, cisplatin, and fluorouracil $v s$ fluorouracil, doxorubicin, and methotrexate in advanced esophagogastric cancer. J Clin Oncol 15: 261-267

Zaniboni A, Barni S, Labianca R, Marini G, Pancera G, Giaccon G, Piazza E, Signaroldi A, Legnani W, Luporini G (1995) Epirubicin, cisplatin, and continuous infusion 5-fluorouracil is an active and safe regimen for patients with advanced gastric cancer. An Italian Group for the Study of Digestive Tract Cancer (GISCAD) report. Cancer 76: $1694-1699$ 